\title{
Establishment of Spiritual Care Service System for Empty Nesters in New Rural Communities
}

\author{
Bo Xing \\ Xi'an Peihua University, Xi’ an, Shaanxi, 710125, China
}

Keywords: new rural communities, empty nester, spiritual care

\begin{abstract}
New rural communities have attached more importance to the improvement of living environment and the building of infrastructures. However, relevant public services fail to keep pace with this trend, particularly the little attention and investment on humanistic care service system building for empty nester. Therefore, it is important for rural communities to strengthen the establishment of spiritual care system for empty nesters to enhance their living quality.
\end{abstract}

\section{Background Analysis}

With the rapid development of urbanization, rural community construction in China has entered into a new stage, which has broken the traditional urban-rural dual pattern in China, being an effective channel for improving public services in rural areas as well as living and production environment of peasants. Accelerating the building of new rural communities is of great significance for speeding up China's urbanization and building a moderately prosperous society in all aspects. As the increasing promotion of China's new rural communities, more and more peasants have left the land where they live by generation after generation. And traditional family supporting pattern has been seriously affected, leaving a large number of empty nesters in rural areas. For empty nesters in rural areas, there are three problems to be solved: one is living security, the second is daily care and the last the spiritual consolation. As the economy and the society develops, empty nesters concern more about spiritual supports and communication rather than basic necessities like food and living. Thus, numerous empty nesters have suffered from a variety of psychological illness even committed suicide because of solitude, loneliness and lack of humanistic care. For instance, on July 22, 2013, Dalan, an elderly woman living in Malu Village, Qiaotou Town, Shizhu County, Chongqing City committed suicide in her family. And in August, 2015, a 85-year-old man called Bao took his own life because he worried that no one could take care of himself when he was ill. All these cases demonstrate the severity of the lack of spiritual comfort for empty nesters in rural areas, and communities shall focus more on spiritual care of senior citizens, actively building humanistic care service system for senior citizens, and helping them cope with mental disturbances, which is a major problem to be solved in new rural community building.

\section{Establishment of Spiritual Care Service System for Empty Nesters in New Rural Communities}

Compared with traditional backward scattered villages, new rural communities have greatly improved living environment. The enhanced infrastructure and elderly care facilities in rural communities have brought bright prospect for the rural elders. Nonetheless, public services in rural communities are relatively backward with many prominent problems in particular the little attention and investment on spiritual care service system for senior citizens. And the following are some specific problems:

\subsection{Under-investment on spiritual comfort service system building for senior citizens}

Despite complete infrastructure and public service facilities in new rural communities, such as nursing home, health station, activity centers for senior citizens and so on, ancillary facilities for elderly care is underestimated with insufficient investment due to the restriction of funds. At present, 
a large part of new rural community building is just a concentration of former resources, while the importance of rural public service and social security system receives little attention. [1] Except few new rural communities with better economic conditions, most rural communities are short of service facilities for elderly care like gerocomium, activity rooms, libraries, fitness centers and entertainment venues, impeding the improvement of spiritual care quality for elders.

\subsection{Insufficient emphasis on organization and guidance of spiritual and cultural life of rural elders paid by communities}

Influenced by traditional elderly care ideas, most new rural communities focus more on daily care of elders but ignore the spiritual care and establishment of spiritual consolation organizations for elders, for example, psychological counseling centers, right-keeping organizations, and interest groups for elders. And the frequency of activities for elders is relatively low, which can be divided into four groups: frequent (10.9\%), few (31.06\%), seldom (22.07\%) and never (35.69\%). Most empty nesters spend their spare time in chatting, walking, watching TV, playing mahjong and other original activities, of course, some elders would like to read, dance, and play ball games, but they only make a small part. [2]

\subsection{Unreasonable human resource setting and insufficient volunteers for elder care service in communities}

Professional personnel working for spiritual care in communities are few other than family members and few volunteers, who cannot meet the needs of spiritual care in rural communities both in quantity and professional level. [3] Currently, some gerocomiums merely offer daily care service instead of meeting their psychological needs and providing spiritual consolation. In addition, a small number of service staffs are just casual laborers with low education level, and most of them have never received systematic elderly care training, thus, they hardly offer spiritual consolation and psychological counseling[4].

\section{Building of humanistic care service system for empty nester in new rural communities}

A prerequisite for promoting new rural communities is to provide public services in rural communities and strengthen rural social security system, for public service level represents an important symbol measuring economic and social development as well as civilization in rural communities. Therefore, building spiritual care system for empty nesters is a necessary part of public service building in communities.

\subsection{Expanding public investment for spiritual support of elders in new rural communities can be started from the following three aspects}

(1) Special spiritual support fund is established to solve this problem for empty elders, which will be particularly listed in the community budget. (2) Build and improve hardware facilities for spiritual care of elders based on communities, for instance, activity centers, libraries, fitness venues, chess and cards rooms, chat rooms for elders. This measure will greatly enhance ancillary facilities as a spiritual support and fulfill their spare time. (3) Establish aging association and psychological counseling centers, help elders safeguard legal rights and deal with psychological problems, which will require full-time staffs and financial support. (4) Establish special service institutions for spiritual care. As a long-term plan, establishing special service institutions in rural communities can transform current casual and scattered services for elder spiritual care and provide lasting and systematic services for empty nesters with sufficient funds and staffs.

\subsection{Explore new home-based care for the aged by motivating other (silver-aged) elders in communities}

Which means that the communities organize healthy and younger elders with high education level to assist elders living alone or losing their only child. At present, home-based care in most sural areas is the major form for the empty elders. Under the increasing aging society and serious 
resource shortage for elderly care, if communities can make full use of these silver-aged elders to arouse their enthusiasm and launch efficient mutual assistance, it will be a sound solution to the problem of spiritual ballast. This model is relatively popular in urban communities, while rural areas are still exploring. And other communities can learn from Xiwadi Community, Fengtai District, Beijing. The community established an autonomous organization in 2008 serving for elders, namely home-based care association. The association consists of seven teams with 125 volunteers in total, whose scope includes seven services like shopping, haircutting, washing beddings, domestic hygiene, heart-to-heart talk, medical care, safe family and so forth. To strengthen long-term management, the association carries out dual-card membership system including red card (representing volunteers) and green card(recipients). All cards are printed with the service call of the association, and residents can make an appointment in advance. Empty nesters, disabled elders and those living in poverty above 60 years old should pay 10 yuan for membership dues (free for the poor), and then they can enjoy all services of volunteers at any time. While free services of volunteers can serve as a loving saving. When a volunteer serves for five years, then he can enjoy the service throughout the life [5]. Association in Xiwadi Community provides a new idea for spiritual consolation of rural empty nesters. For rural communities, they should adjust measures to local conditions and make preparations in advance to make full use of silver-aged elders.

\subsection{Strengthen publicity of spiritual care and filial piety education for elders and create an atmosphere respecting the elderly}

First, it is necessary to conduct vigorous publicity about laws and legislations of spiritual care by multiple channels like TV, broadcast, and blackboard newspaper. All these measures aim to make children know that elder care includes both material care and spiritual care, which are their bounder responsibilities. Meanwhile, the elders should be guided to learn the troubles of their children, and raise their right-protection awareness. In face of maltreat, insult, hit, discard and other actions failing to support parents, parents shall exercise litigious right. Secondly, strengthen filial piety education and nourish an atmosphere respecting the aged. Considering emotional loneliness of rural empty nesters, the communities should make publicity and education work, praise models respecting and providing for elders to create a sound social atmosphere to respect, concern and help elders. And migrant workers should respect parents and often make contact with their parents, send money and gifts to elders to make them not worry about future life. At the same time, township government, village committees and neighborhood committees should report a case to the security authorities or support prosecution when insulting and beating of parents happens. If necessary, primary-level organizations can sign a dual agreement between parents and children, meaning that children should shoulder dual responsibilities materially and spiritually. And dual agreement should stipulate the time, number of times, tabooed words of visiting parents to make spiritual care more specific, and promote the transformation of qualitative change from quantitative change, preventing material support from replacing emotional support.

\subsection{Establish a variety of interest groups and enrich spiritual life of elders in communities}

The communities should guide empty nesters to establish interest groups of all kinds. Elders should select their team leaders, stipulate management rules and organize entertainment activities like sports, dance, singing, drawing and paper cutting. For interest groups of elders, the communities should give financial support and offer venues. The establishment of interest groups can not only increase communication among elders, expand their social contact, but enrich their spiritual life to eliminate their loneliness and feel happiness.

\subsection{Strengthen talent building for spiritual care of elders, launch psychological counseling training for elders regularly}

Help staffs learn more about psychological knowledge targeted at elders and improve their professional service. At the same time, details of empty nesters should be paid much attention by party members and volunteers and be included into the record. For those party members and volunteers satisfying elders with quality services, they should be prized with political title to foster 
more party members to actively join the team of elderly care and inject new blood to the service team.

\subsection{Encourage elders to take an active part in the social activities}

As activity theory says, elders can overcome negative emotions caused by interruption of their social roles by engaging in new activities and build new images, which means they should rediscover themselves[6]. Therefore, the communities should create conditions for elders to participate in social events and help them contact the society, do some work within their power to find their sense of existence. And the communities should encourage elders with technical background to transmit scientific and cultural knowledge, provide guidance for agriculture, launch counseling service. And they should be supported to improve civic moral construction, public welfare establishments, public security, social tradition transformation, civil mediation, and cultural activities in the communities to educate the next generation. And various human resource intermediary service institutions should be encouraged to conduct matching services between senior talents and social needs to help elders play their part in the society. "Worthiness award" for elders should be carried out regularly to recognize their contributions.

\section{References}

[1] Liu Fang. Analysis on the old-age care in new rural communities [J]. Journal of Science, 2014(4).

[2] Bi Hongxia, Wang Qian, Jiao Hua. An empirical analysis of the old-age pension problem of rural empty nesters [J]. Journal of Shandong Agricultural University (social science edition), 2015(6).

[3] Zhou Xianglian and Liu Ying. On the government responsibility of the elderly in rural empty-nesters [J]. Journal of Social Science of Hunan Normal University, 2014(8).

[4] Zhao Qiaofeng. The problem of the spiritual support of rural empty nesters [J]. Cooperative Economy and Technology, 2016(14).

[5] Shi Hua. Associations warm empty nesters [J]. Elderly Education (Home for the Elderly), 2008(12).

[6] Wu Xian. An effective way to explore the social participation of the elderly [J]. Journal of Education College, Lanzhou, 2011 (5). 